\title{
Tooth Number Matching and Its Software Development for 2KH Planetary Gear Mechanism
}

\author{
Jin-Feng SUN, Jun WANG*, Yun-Duan HONG, Hong-Xiu HE, Quan WANG, \\ Jun REN, Sheng-Lan MAO, Shu-Ting LI, Zheng-Zheng QIN, Xing HONG
}

School of Mechanical Engineering, Hubei University of Technology, Wuhan, hubei, 430068, China

*junwang@mail.hbut.edu.cn

Keywords: 2K-H, Planetary gear, Tooth number matching, Computation.

\begin{abstract}
K-H planetary gear is a commonly seen gear structure, but it has proven troublesome to match its tooth numbers through hand computation. This paper introduces a calculation method for the $2 \mathrm{~K}-\mathrm{H}$ planetary gear and develops a software written with the use of computer software technology for matching gear units, thus greatly reducing the workload in matching tooth numbers. In addition, they can be applied to tooth number matching for all kinds of $2 \mathrm{~K}-\mathrm{H}$ planetary gears.
\end{abstract}

\section{Introduction}

In calculating the tooth numbers for the $2 \mathrm{~K}-\mathrm{H}$ planetary gear, due to its many limitations, we often need to resort to hand computation, thus making the tooth number matching extremely complex. Moreover, hand computation is time-consuming, because the $2 \mathrm{~K}-\mathrm{H}$ planetary gear involves four different kinds of gear mechanisms. At present, a growing number of designing personnel have begun to complete this task through computers since they came out. This paper introduces the experience of realizing the tooth number matching for $2 \mathrm{~K}-\mathrm{H}$ planetary gear through computer programs.

\section{K-H Planetary Gear Mechanism}

2K-H planetary gear mechanism is featured by small size, high self-weight transmission efficiency, light weight, large transmission ratio, low noise and high reliability, etc. With the development of science and technology, planetary gearing has been widely applied into the machinery of such fields as metallurgy, mining, lifting, chemical engineering, electrics, textile and oil production. However, planetary gearing is a highly advanced system, especially all kinds of large-scale reducers. To satisfy the work needs and ensure relatively high operating reliability and longer service life of the mechanical system, we can not willfully choose the tooth number for each gear in designing the planetary gear mechanism; but instead, we have to work out the correct tooth number for the planetary gears according to the schematic diagrams and satisfy certain conditions according to the characteristics of planetary transmission, with a view to guaranteeing normal operation. By virtue of our needs, we divide the planetary gear into four kinds as evidenced by the following figures, namely $2 \mathrm{KH}-\mathrm{NGW}, 2 \mathrm{KH}-\mathrm{WW}, 2 \mathrm{KH}-\mathrm{NW}$ and $2 \mathrm{KH}-\mathrm{NN}$, among which $\mathrm{N}$ stands for internal gear, $\mathrm{W}$ for external gear and $\mathrm{G}$ for composite gear.

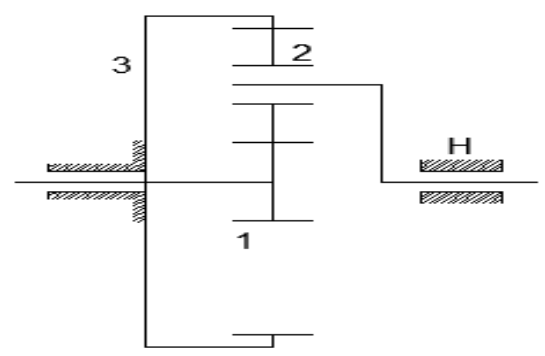

Fig1. 2KH-NGW planetary gear mechanism

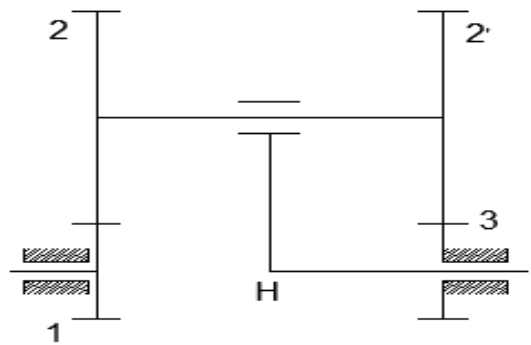

Fig 2. 2KH-WW planetary gear mechanism 


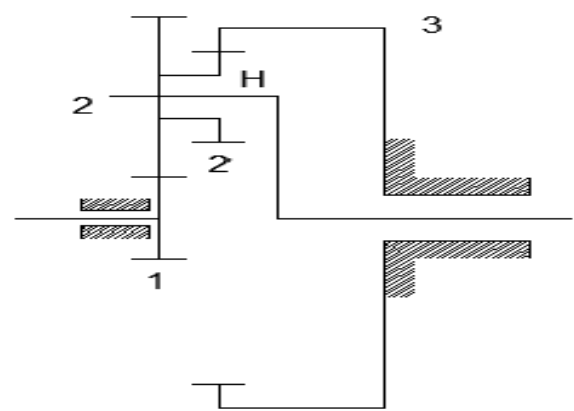

Fig 3. 2KH-NW planetary gear mechanism

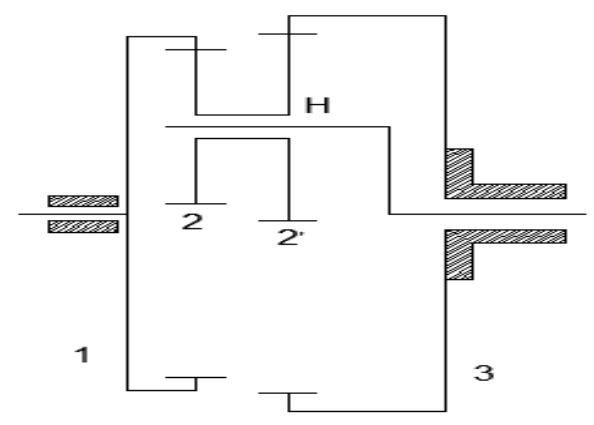

Fig 4. 2KH-NN planetary gear mechanism

\section{Restrictive Conditions for Tooth Number Matching}

In designing the $2 \mathrm{KH}$ planetary gear mechanism, the tooth number matching of gears must satisfy the following conditions under normal circumstances:

\section{Condition for Transmission Ratio}

It refers to a condition which must be satisfied for the tooth numbers of each gear to achieve the given transmission ratio. And the transmission ratio for $2 \mathrm{~K}-\mathrm{H}$ planetary gear train is:

$$
i_{a H}^{b}=1-i_{a b}
$$

According to the above formula, the tooth number ratio of the two central gears of the $2 \mathrm{KH}-\mathrm{NGW}$ planetary gear train can be obtained. And the condition for the transmission ratio should be:

$$
\frac{Z_{b}}{Z_{a}}=i_{a b}-1
$$

To the planetary gear train with planetary gears being the dual gears $(\mathrm{g}-5)$ of $2 \mathrm{KH}-\mathrm{NW}(\mathrm{WW}, \mathrm{NN})$ types, the condition for the transmission ratio should be:

$$
\frac{Z_{g} Z_{b}}{Z_{a} Z_{f}}= \pm i_{a H}^{b}-1
$$

In the formula, the "+" symbol applies to minus-sign gear train (NW) while the "-" symbol applies to plus-sign gear train (WW or NN).

\section{Condition for Concentricity}

It refers to a condition to ensure the axial alignment of basic building blocks. The center distance for two pairs of gears must be identically equal, that is,

$$
a_{a g}^{\prime}=a_{b f}^{\prime}
$$

Or

$$
m_{a g}\left(Z_{a} \pm Z_{g}\right) \frac{\cos \alpha}{\cos \alpha_{a g}^{\prime}}=m_{b f}\left(Z_{b} \pm Z_{f}\right) \frac{\cos \alpha}{\cos \alpha_{b f}^{\prime}}
$$

After calculation:

$$
\frac{m_{a g}\left(Z_{a} \pm Z_{g}\right)}{\cos \alpha_{a g}^{\prime}}=\frac{m_{b f}\left(Z_{b} \pm Z_{f}\right)}{\cos \alpha_{b f}^{\prime}}
$$

In the formula, the "+" symbol applies to external gearing while the "-" symbol applies to 
internal gearing; $\alpha$ stands for the pressure angle of the reference circle; $\alpha^{\prime}{ }_{\text {ag }}$ and $\alpha^{\prime}{ }^{\prime}$ ff stand for the generating angles after changes to the angles of the two pairs of gears; $m_{a g}$ and $m_{b f}$ stand for the modulus of the two pairs of gears. Different standards can be adopted, but in practical application, $\mathrm{m}_{\mathrm{ag}}=\mathrm{m}_{\mathrm{bf}}$.

$$
\begin{gathered}
\frac{\left(Z_{a}+Z_{g}\right)}{\cos \alpha_{a g}^{\prime}}=\frac{\left(Z_{b}+Z_{f}\right)}{\cos \alpha_{b f}^{\prime}} \\
Z_{g}=\frac{Z_{b}-Z_{a}}{2}
\end{gathered}
$$

\section{Condition for Fitting}

To fit the several planetary gears on the tumbler $\mathrm{H}$ (planetary frame) into the spaces between two central gears evenly, the condition to be satisfied by each tooth number of gears is known as the condition for fitting.

The unified formula for $2 \mathrm{KH}$ planetary gear train with dual gears as the planetary gears is:

$$
q=\frac{Z_{a} Z_{f} \pm Z_{g} Z_{b}}{n_{p}}=\text { an integer }
$$

In the formula, $Z_{\mathrm{f}}$ and $\mathrm{Z}_{\mathrm{g}}$ stand for tooth numbers, the values of which are obtained through dividing them by the common divisor $\mathrm{m}$.

$$
q^{\prime}=\frac{\left(Z_{a}+Z_{b}\right)}{n_{p}}=\text { an integer }
$$

For the $2 \mathrm{KH}-\mathrm{NGW}$ planetary gear train, due to $\mathrm{Z}_{\mathrm{f}}=\mathrm{Z}_{\mathrm{g}}$ with matching together, the following can be obtained from the formula (3-7). This is the condition for fitting.

\section{Condition for Adjacency}

In order to avoid collisions between the planetary gears, certain spaces must be reserved; that is to say, the center distance $\mathrm{L}$ of the central gears in two adjacent lines must be larger than the tip diameter $\mathrm{d}_{\mathrm{ag}}$ of the planetary gear in the digest lines. The formula is:

$$
L>d_{a g}
$$

\section{Software Development}

The limitations in tooth number matching for planetary gears present a great deal of difficulties. Therefore, we, on the basis of the VC2008 programming software, have written a special program for tooth number matching, named the program of tooth number matching for $2 \mathrm{KH}$ planetary gear mechanism. According to the input transmission ratio and the number of planetary gears to be matched, the program can automatically work out the tooth number matching scheme meeting the above-mentioned restrictive conditions for gear and gear ring as well as the transmission ratio errors for corresponding gears. 


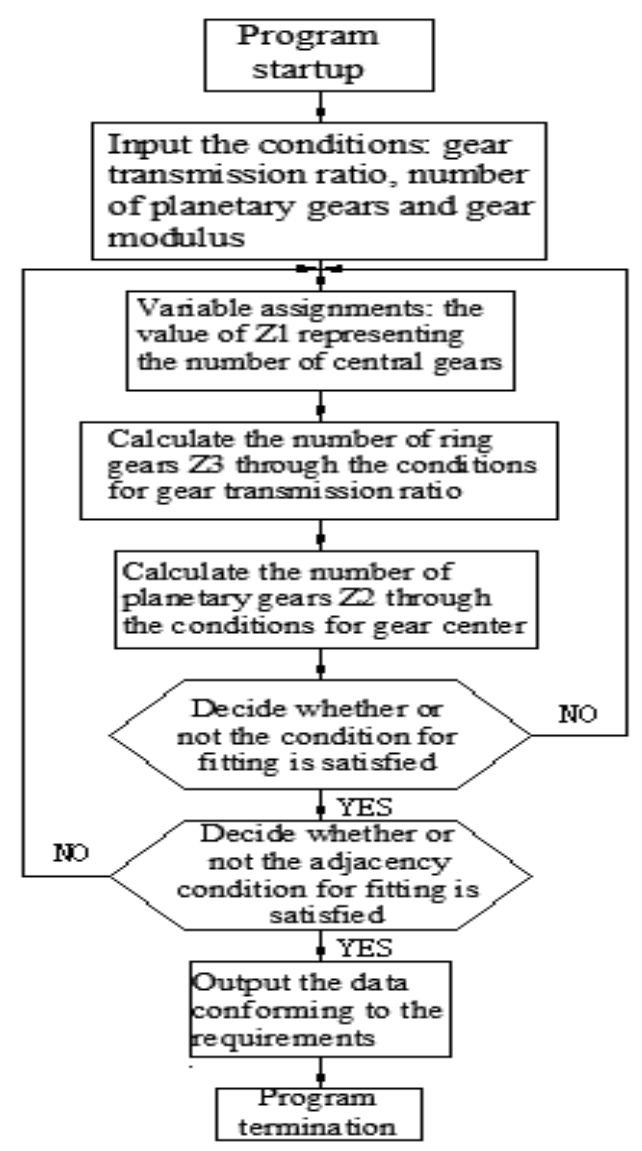

Fig.5: Program flowchart of tooth number matching for $2 \mathrm{KH}$ planetary gear mechanism

In accordance with the above flowchart, the main interface of our software for tooth number matching is shown as in the following Fig. Firstly, we choose the types of $2 \mathrm{KH}$ planetary gears, then type in the transmission ratio, number of planetary gears and gear modulus (three conditions to be input by the user) in the middle, and finally the tooth number matching result we need will be pop up at the right side. The software interface is shown in Fig.6.

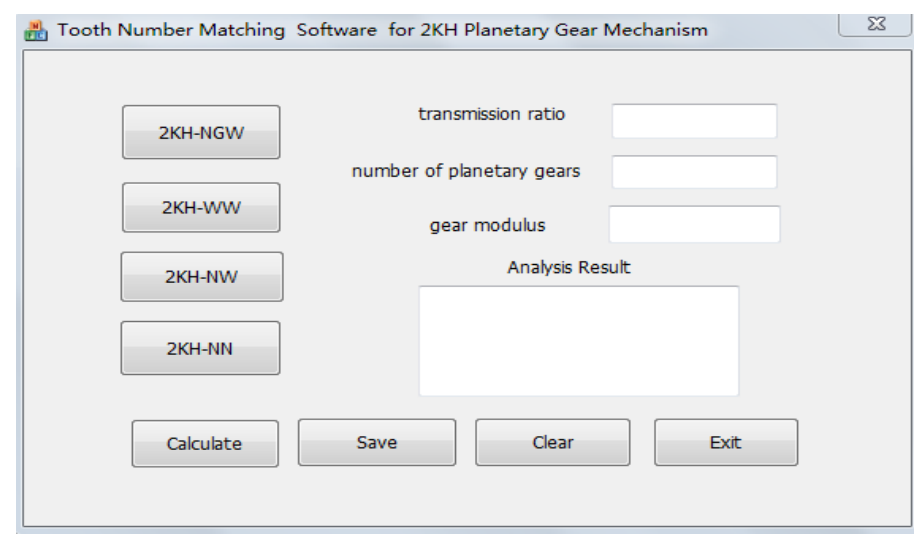

Fig.6: program software interface of tooth number matching for $2 \mathrm{KH}$ planetary gear mechanism

\section{Calculation Examples}

If it is to design a $2 \mathrm{KH}-\mathrm{NGW}$ planetary gear train with a transmission ratio of $\mathrm{i}_{\mathrm{aH}}{ }^{\mathrm{b}}=4.55$, the tooth number for each gear shall be determined.

According to the requirements of the question, we should firstly start the software, click the button of $2 \mathrm{KH}-\mathrm{NGW}$, and then assign $4.55,4$ and 3 to the values of the transmission ratio, number of planetary gears and gear modulus. After the input, when we click the calculate button, several 
results will be produced. Take the result of "the transmission ratio error is $0.10 \%$, the tooth number of external gear rings is 78 , the number of planetary gears is 28 and the tooth number of central gears is 22 " as one example. We can choose the optimal result and thus complete the whole process of tooth number matching for $2 \mathrm{KH}$ planetary gear mechanism.

\section{Conclusions}

In light of the composition features of $2 \mathrm{KH}$ planetary gear mechanism and the restrictive conditions for its tooth number matching, the mathematical calculation method for $2 \mathrm{KH}$ planetary gear mechanism is established. Through this method, we work out the tooth number matching of planetary gears, and transfer it into computer languages. With the help of VC software programming, the tooth number of planetary gears can be calculated by computer programs. The developed software is featured by simple operation, strong man-machine interaction, user-friendly interface and wide usage.

\section{Acknowledgments}

We are grateful for the support from the Scientific Research Program Funded Project (No.: B2016044) of Hubei Provincial Department of Education to the research of this paper.

\section{References}

1. Hong-Wei NI. Tooth number matching of planetary differential transmission mechanism[J]. Mechanical Engineer, 2002.

2. Hong-Yan SHI, Hai-Hong CHEN, Yu ZHENG, Xuan YU. Optimization Design of 2K-H(NGW)-Z Mixed Gear Train based on Matlab Genetic Algorithm[J]. Journal of Mechanical Transmission, 2011.

3. Zhao-Shan YANG, Ming CHEN. The Mesh Efficiency of the Planetary Mechanism of 2K-H[D] Style[J]. Journal of China Textile University, 1998.

4. Qi-Min XIAO, Nai-Sen CAO, Xiao-Guang SUN. The Study on Optimal Design System of 2K-H Planetary Gear Train[J]. Development \& Innovation of Machinery \& Electrical Products, 2006.

5. Shu-Yan WANG, Peng-Fei MA. The optimization design of the $2 \mathrm{~K}-\mathrm{H}$ planetary gear transmission system[J]. Construction Mechanization, 2002.

6. Yue LIU, Ming MAO, Ming-Cheng WANG. Optimal Design and Accurate Intensity Check of 2K-H Planetary Transmission System[J]. Vehicle \& Power Technology, 2011.

7. Zhen-Jie ZHAO, Yong ZHANG, Yu-Jun WANG. 2K-H-based Multi-stage Planetary Gear Reducer Optimization Design System[J]. Computer Programming Skills \& Maintenance, 2011.

8. Xiao-Chun HUANG. Design and Application of Planetary Gear Transmission Mechanism[J]. Electro-Mechanical Engineering, 1997.

9. Lai-Hu Yu. Optimal Design of 2K-H Planetary Gear Mechanism[J]. Journal of Hebei Radio \& TV University, 1999.

10. Ruo-Hui WANG. The Planet Gear-Driven Optimum Programming[J]. Journal of Electric Power, 2002.

11. Nan GE, Jun ZHANG. Finite Element Analysis of Internal Gear in High-Speed Planetary Gear Units[J]. Transactions of Tianjin University, 2008.

12. Ying YU, Bo YU. Analysis and Design of Gear Train[M]. Harbin: Harbin Engineering University Press, 2007.

13. Chao HU. Visual C++ the Easy Way[M]. Electronic Industry Press, 2013.

14. Wei WANG, Xiao-Jian WANG. Mechanical Design( $2^{\text {nd }}$ edition)[M]. Huazhong University of Science and Technology Press, 2012.

15. Bing WEI, Quan-Yu YU, Wei SUN. Mechanical Principles[M]. Huazhong University of Science and Technology Press, 2011. 